\title{
Electronic Detection of Biomarkers by Si Field-Effect Transistor from Undiluted Sample Solutions with High Ionic Strengths
}

\author{
Chil Seong Ah, ${ }^{*}$ Ansoon Kim, Wan-Joong Kim, Chan Woo Park, Chang-Geun Ahn, \\ Jong-Heon Yang, In Bok Baek, Tae-Youb Kim, and Gun Yong Sung* \\ Biosensor Research Team, Electronics and Telecommunications Research Institute, Daejeon 305-700, Korea \\ *E-mail: acs@etri.re.kr(C.S.A),gysung@etri.re.kr(G.Y.S) \\ Received January 7, 2010, Accepted March 29, 2010
}

\begin{abstract}
In this study, we have developed a new detection method using Si field effect transistor (FET)-type biosensors, which enables the direct monitoring of antigen-antibody binding within very high-ionic-strength solutions such as $1 \times \mathrm{PBS}$ and human serum. In the new method, as no additional dilution or desalting processes are required, the FET-type biosensors can be more suitable for ultrasensitive and real-time analysis of raw sample solutions. The new detection scheme is based on the observation that the strength of antigen-antibody-specific binding is significantly influenced by the ionic strength of the reaction solutions. For a prostate specific antigen (PSA), in some conditions, the binding reaction between PSA and anti-PSA in a low-ionic strength reaction solution such as $10 \mu \mathrm{M}$ phosphate buffer is weak (reversible), while that in high-ionic strength reaction solutions such as $1 \times \mathrm{PBS}$ or human serum is strong.
\end{abstract}

Key Words: Electronic detection, PSA, Si field effect transistor (FET), Ionic strength, Real-time

\section{Introduction}

Field effect transistor (FET)-type immunosensors are of considerable interest not only scientifically but also industrially, with their ability of real-time, label-free, highly-sensitive, and direct electrical detection of various biomarkers. ${ }^{1-8}$ In the FET immunosensor, a certain type of receptors are immobilized on the channel surface, so that the specific binding of charged target molecules to the receptors can be detected from the change of the channel conductance between the source and drain electrodes. As the channel conductance is also dependent on the $\mathrm{pH}$ or salt concentration of sample solutions, most previous works have

(a)

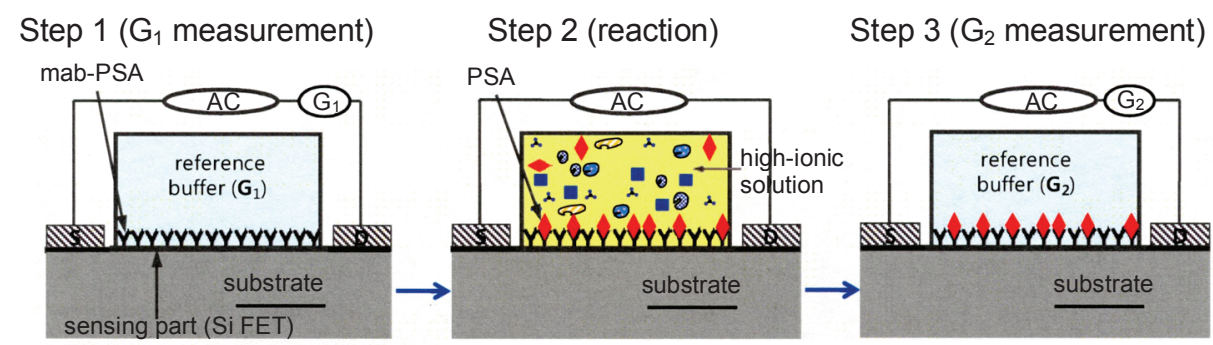

(b)

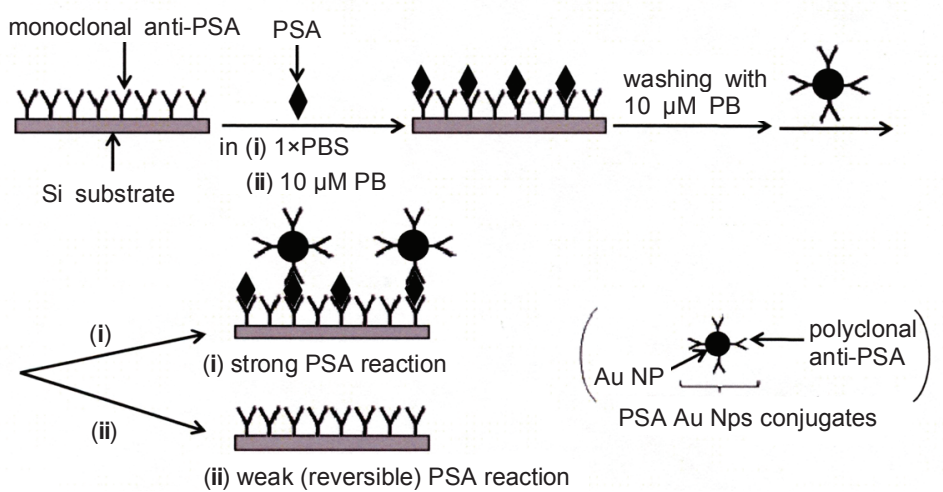

Figure 1. (a) Schematic diagram for directly detecting biomarkers in high-ionic-strength solutions without dilution or desalting. The saturation conductance $\mathrm{G}_{1}$ was measured while flowing a reference buffer solution (step 1), and $\mathrm{G}_{2}$ was measured while reflowing the reference buffer solution after removing the remaining biomarker solution (step 3). The antigen-antibody binding reaction was performed in high-ionic-strength solutions such as $1 \times P B S$ (step 2) (Debye length $\sim 0.7 \mathrm{~nm}^{3}$ ). Signal conductance $\Delta \mathrm{G}$ was obtained by the difference of the saturation conductances $\mathrm{G}_{1}$ and $\mathrm{G}_{2}$. (b) Schematic diagram showing the dependence of the weak/strong binding reaction between antigen and antibody on the ionic strength of reaction solution by the sandwich-type pab-PSA Au-Np conjugate immunoassay. Route i: antigen-antibody binding reaction in high-ionic-strength solution such as $1 \times \mathrm{PBS}$; route ii: antigen-antibody binding reaction in low-ionic-strength solution such as $10 \mu \mathrm{M}$ PB. 
been performed only in precisely controlled conditions with low salt concentrations $(<1 \mathrm{mM}$ ), for preventing the screening of electrical signals from the charge of target biomarkers. ${ }^{2,3-7}$ However, for practical situation using the human serum or plasma, it is still difficult to achieve consistent and accurate diagnostics covering the wide range of $\mathrm{pH}$ or ionic strength of raw sample solutions.

In the present work, we have developed a new detection method for Si FET-type biosensors, which is independent of the $\mathrm{pH}$ and ionic strength of the sample solution. The strength of antigen-antibody-specific binding was observed to be significantly influenced by the ionic strength of the reaction solution. When the specific binding between prostate specific antigen (PSA) and anti-PSA was achieved in a reaction solution with low ionic strength (10 $\mu \mathrm{M}$ phosphate buffer), subsequent washing with a low-ionic-strength buffer solution led to complete dissociation of the PSA-anti-PSA complexes (weak binding). In contrast, when the specific binding reaction was performed in a highionic-strength solution $(1 \times \mathrm{PBS})$, most of the PSA-anti-PSA bindings were maintained even after the same washing step Such phenomena were confirmed by SEM analysis of gold nanoparticle ( $\mathrm{Au} \mathrm{Np}$ ) coverage after a sandwich-type anti-PSA AuNp conjugate immunoassay, as well as by fluorescence analysis using enzyme-linked immunosorbent assay (ELISA). Based on those observations, the electronic detections of biomarkers in high-ionic-strength solutions such as $1 \times \mathrm{PBs}$ or human serum were conducted in three steps, as follows. As shown in Figure $1 \mathrm{a}$, in step 1 , the initial saturation conductance $\mathrm{G}_{1}$ is measured while flowing a reference buffer solution (precisely controlled low ionic buffer solution). In step 2, the antigen-antibody binding reaction is performed in a high-ionic-strength reaction solution, such as $1 \times \mathrm{PBS}$ or human serum. Finally, in step $3, \mathrm{G}_{2}$ is measured after removing the remaining PSA solution by flowing the reference buffer solution again. Signal conductance $\Delta \mathrm{G}$ is obtained from the difference between the saturation conductances before and after the binding reaction, $G_{1}$ and $G_{2}$.

\section{Experimental Section}

Reagents and immunoreaction buffer. Deionized water (18 $\mathrm{M} \Omega \cdot \mathrm{cm}$, Millipore) was used in all experiments. A PSA-free, monoclonal antibody of PSA (host: mouse, mab-PSA, affinity constant $\sim 2 \times 10^{10} \mathrm{~L} / \mathrm{M}$ ), a polyclonal antibody of PSA (host: goat, pab-PSA), and total mouse IgG were purchased from Fitzgerald. The above proteins were used after a quality check by ELISA immunoassay. Bovine serum albumin (BSA), human serum, aminopropyl triethoxysilane (APTES), sodium citrate tribasic dihydrate, and hydrogen tetrachloroaurate (III) trihydrate were purchased from Sigma-Aldrich. An aqueous 50\% glutaraldehyde solution was purchased from Fluka. Polystyrene 96-well microtiter plates (Nunc) were used to perform the ELISA analysis. In our sensing measurements and ELISA experiments, we used dilutions of phosphate buffered saline (PBS); these dilutions were made relative to $1 \times \mathrm{PBS}$, which contains $138 \mathrm{mM} \mathrm{NaCl}, 3 \mathrm{mM} \mathrm{KCl}$, and $10 \mathrm{mM}$ phosphate salts (monobasic and dibasic; Sigma-Aldrich). The buffer solutions (pH 7.4) for the ELISA were as follows: (a) coating buffer: $1 \times$ PBS (Sigma), (b) assay buffer: casein blocker in $1 \times$ PBS (Pierce), $0.1 \times$
PBS, $0.01 \times$ PBS, $0.001 \times$ PBS, and $0.0001 \times$ PBS, (c) washing buffer: casein blocker in PBS right after coating, $0.001 \times$ PBS after immunoassay.

Preparation of the pab-PSA Au Nps conjugates. Au-Nps were prepared by the reduction of $\mathrm{HAuCl}_{4}$ with sodium citrate. ${ }^{9}$ Briefly, after boiling a $500 \mathrm{~mL}$ aqueous solution of $1 \mathrm{mM} \mathrm{HAuCl}_{4}$ with $38 \mathrm{mM}$ trisodium citrate for $10 \mathrm{~min}$, the resulting colloidal suspension was cooled and filtered through a $0.45-\mu \mathrm{m}$ Millipore membrane. The diameter of the Au Nps was approximately 15 $\mathrm{nm}$, based on transmission electron microscopy (TEM) analysis. The pab-PSA Au Nps conjugates was prepared as follows. A $40 \mathrm{mM} \mathrm{K}_{2} \mathrm{CO}_{3}$ solution was used to adjust the $\mathrm{pH}$ of $1 \mathrm{~mL}$ of $2 \mathrm{nM}$ Au Nps solution to $\mathrm{pH} 9$. After about $30 \mathrm{~s}, 81 \mu \mathrm{L}$ of a 100 $\mu \mathrm{g} / \mathrm{mL}$ solution of pab-PSA were added ([pab-PSA] / [Au $\mathrm{Nps}]=27$ ). Two min later, $100 \mu \mathrm{L}$ of a $10 \%$ BSA solution were added. The solution was mixed thoroughly by shaking for 20 $\mathrm{min}$ at room temperature, followed by centrifugation for at least $25 \mathrm{~min}$ at $20,000 \mathrm{~g}$ and $4{ }^{\circ} \mathrm{C}$ to remove excess reagents. After decanting the supernatant, the resulting precipitate was resuspended in $1 \mathrm{~mL}$ of $10 \mathrm{mM}$ phosphate buffer ( $\mathrm{pH} 7$ ) solution containing $1 \% \mathrm{BSA}$. Immediately following centrifugation for $20 \mathrm{~min}$ at $20,000 \mathrm{~g}$ and $4{ }^{\circ} \mathrm{C}$ and removal of the supernatant, the precipitate was resuspended in $1 \mathrm{~mL}$ of $1 \times \mathrm{PBS}$ containing $0.1 \%$ $\mathrm{NaN}_{3}$ and $1 \% \mathrm{BSA}$. The conjugates prepared by using this method are stable for at least one month when preserved at $4{ }^{\circ} \mathrm{C}$.

Immunoassay using the anti-PSA-Au-Nps conjugates. A schematic for the sandwich-type pab-PSA Au Nps conjugates immunoassay is shown in Figure 1b. First, APTES self-assembly monolayer (SAM) was formed on a $2 \times 2 \mathrm{~cm}^{2}$ bulk Si substrate via a silanization reaction. ${ }^{7,10-17}$ Immediately thereafter, the APTES-immobilized Si substrate was immersed in a $25 \mathrm{wt} \%$ glutaraldehyde solution containing $4 \mathrm{mM} \mathrm{NaBH}_{3} \mathrm{CN}(\mathrm{pH}$ 8.4) for $4 \mathrm{~h}$ for the formation of aldehyde functional groups (-CHO) on the silicon channels. Finally, the chip functionalized with the aldehyde group was immersed in a $250 \mu \mathrm{g} / \mathrm{mL}$ solution of mabPSA antibody ( $4 \mathrm{mMNaBH}_{3} \mathrm{CN}, \mathrm{pH} 8.4$ ) overnight, and the sensor was then immersed in a $1 \%$ BSA solution $\left(4 \mathrm{mMNaBH}_{3} \mathrm{CN}\right.$, $\mathrm{pH}$ 8.4) for approximately $1 \mathrm{~h}$ to block aldehyde functional groups that did not react with the mab-PSA. Specific binding between the mab-PSA and PSA was conducted in a microfluidic system using a $50 \mathrm{ng} / \mathrm{mL}$ solution of PSA at a flow rate of 25 $\mu \mathrm{L} / \min$ (Table 1). Finally, a $0.5 \mathrm{nM}$ pab-PSA Au Nps conjugates (in $1 \times$ PBS containing $0.1 \% \mathrm{NaN}_{3}$ and $1 \% \mathrm{BSA}$ ) solution was allowed to flow into the microfluidic system at a flow rate of $25 \mu \mathrm{L} / \mathrm{min}$ for $1 \mathrm{~h}$, thereby inducing the reaction between antigen and antibody (Table 1).

Immunoassay protocol using sandwich ELISA method. Polystyrene 96-well microtiter plates were coated with $5 \mu \mathrm{g} / \mathrm{mL}$ mab-PSA (Fitzgerald) solution in $1 \times$ PBS for $2 \mathrm{~h}$, followed by blocking of the unreacted plate with casein blocker. The $5 \mathrm{ng} / \mathrm{mL}$ PSA antigen (Fitzgerald) solutions were added to the mab-PSA coated plate, followed by adding PSA conjugates (pab-PSA conjugated with horseradish peroxidase (HRP)). TMB solution as a substrate reacted with the HRP for $20 \mathrm{~min}$, and the reaction was stopped then by $\mathrm{HCl}$ solution. The concentration of immunoreacted PSA antigen was detected by monitoring the absorbance at $450 \mathrm{~nm}$ using ELISA reader.

Fabrication of Si FET devices and electrical measurements. 
Table 1. Reaction conditions and number of Nps counted from the data in Figure 2. Degree of antigen-antibody binding according to the ionic strength of the reaction solution used in PSA binding to the mab-PSA immobilized on the bulk Si substrate in the sandwich-type pab-PSA Au-Nps conjugate immunoassay. (a)-(c): Antigen-antibody binding reaction followed by washing for (a) 0 , (b) 10 , and (c) 30 min in a low-ionic-strength $10 \mu \mathrm{M}$ PB solution after PSA binding for $30 \mathrm{~min}$ in a high-ionic-strength $1 \times$ PBS reaction solution. (d)-(f): Antigen-antibody binding reaction followed by washing for (d) 0 , (e) 10 , and (f) $30 \mathrm{~min}$ in low-ionic-strength $10 \mu \mathrm{M}$ PB after PSA binding for $30 \mathrm{~min}$ in low-ionic-strength $10 \mu \mathrm{M}$ PB solution. (g) Non-specific binding test (NSB). Flow rates of reaction buffer solution and washing buffer solution were $25 \mu \mathrm{L} / \mathrm{min}$, and that of the conjugates solution was $500 \mu \mathrm{L} / \mathrm{h}$

\begin{tabular}{|c|c|c|c|c|c|c|}
\hline Figure 2 & $\begin{array}{l}\text { concentration of } \\
\text { PSA }\end{array}$ & $\begin{array}{l}\text { reaction buffer solution } \\
(\mathrm{pH} 7.4)\end{array}$ & $\begin{array}{l}\text { PSA reaction time } \\
(\text { (min) }\end{array}$ & $\begin{array}{l}\text { washing time with } \\
10 \mu \mathrm{M} \text { PB (min) }\end{array}$ & $\mathrm{Au} \mathrm{Nps} / \mu \mathrm{m}^{2}$ & relative ratio ${ }^{a}$ \\
\hline $\mathbf{a}$ & $50 \mathrm{ng} / \mathrm{mL}$ & $1 \times \mathrm{PBS}$ & 30 & 0 & 447 & 1 \\
\hline b & $50 \mathrm{ng} / \mathrm{mL}$ & $1 \times \mathrm{PBS}$ & 30 & 10 & 453 & 1.01 \\
\hline c & $50 \mathrm{ng} / \mathrm{mL}$ & $1 \times \mathrm{PBS}$ & 30 & 30 & 454 & 1.01 \\
\hline d & $50 \mathrm{ng} / \mathrm{mL}$ & $10 \mu \mathrm{M}$ PB & 30 & 0 & 411 & 0.92 \\
\hline e & $50 \mathrm{ng} / \mathrm{mL}$ & $10 \mu \mathrm{M}$ PB & 30 & 10 & 137 & 0.31 \\
\hline f & $50 \mathrm{ng} / \mathrm{mL}$ & $10 \mu \mathrm{M}$ PB & 30 & 30 & 21 & 0.05 \\
\hline g & no & NSB test & no & no & 18 & 0.04 \\
\hline
\end{tabular}

${ }^{a}$ Relative ratio is Au Nps of a over Au Nps of a to $\mathbf{g}$.

A silicon-on-insulator (SOI) substrate was used to fabricate p-type doped Si FET immunosensors. ${ }^{7}$ The SOI substrate consisted of a 100-nm thick top Si layer (14 - $22 \Omega \cdot \mathrm{cm},(100))$ and a 200-nm thick buried oxide (BOX) layer. The p-type doped silicon nanochannels were formed by ion implantation of boron (B) in the top silicon layer. After doping and reducing the thickness of the SOI layer to $40 \mathrm{~nm}$ using a wet-thinning process, nanochannels of the desired width were formed within the SOI layer using the photolithography and dry-etching method. Each chip contained several nanochannels; the height of the nanochannels was adjusted to $40 \mathrm{~nm}$, and the width ranged from 150 to $1000 \mathrm{~nm}$. Finally, metal electrodes were formed by electron-beam evaporation of an $\mathrm{Au} / \mathrm{Cr} / \mathrm{Al}$ multilayer (layer thickness: $50 \mathrm{~nm} / 5 \mathrm{~nm} / 50 \mathrm{~nm}$ ), followed by annealing at $400{ }^{\circ} \mathrm{C}$ for $30 \mathrm{~min}$. The doping concentration of Si nanochannels was $8 \times$ $10^{17} \mathrm{~cm}^{-3}$. For the Si FET immunosensors, the Si surface was modified with a mab-PSA and IgG through covalent linkage, and the antibody density was quantified by a sandwich-type pabPSA Au-Np conjugate immunoassay. ${ }^{7}$ Changes in electrical conductance were measured using a lock-in amplifier $(31.47 \mathrm{~Hz}$, $\mathrm{V}_{\mathrm{p}-\mathrm{p}}=20 \mathrm{mV}$ ) by alternating the flow of reference buffer and reaction buffer solutions into the polydimethylsiloxane (PDMS) microchannel (width, $300 \mu \mathrm{m}$; height, $150 \mu \mathrm{m}$ ). Several different Si nanochannels were monitored simultaneously by using a switch matrix system (Keithley 707 switching matrix). Reference buffer solutions (or washing buffer solution) were $10 \mu \mathrm{M}$ phosphate buffer $(+20 \mu \mathrm{M} \mathrm{NaCl})(10 \mu \mathrm{M} \mathrm{PB})$. The concentrations of the cancer markers in the initial human serum (from human male AB plasma; Sigma-Aldrich) were measured by the sandwich ELISA immunoassay. Cancer markers were added to the human serum to produce a serum with the desired concentration of each marker.

\section{Results and Discussion}

Figure 2 shows the scanning electron microscopy (SEM) images of Nps captured during the pab-PSA Au Nps conjugates immunoassay, which demonstrate the dependence of binding strength between the antigen and antibody on the ionic strength of reaction solutions. Figures 2a-c are SEM photographs taken $1 \mathrm{~h}$ after the antigen-antibody reaction of PSA by the pab-PSA Au Nps conjugates, followed by washing with the low-ionicstrength $10 \mu \mathrm{M} \mathrm{PB}(\mathrm{pH} 7.4$ ) for 0,10 , and 30 min, respectively. The specific binding reaction between the mab-PSA on the $\mathrm{Si}$ substrate and the PSA was performed within a high-ionicstrength $1 \times$ PBS reaction solution ( $\mathrm{pH} 7.4$ ) for $30 \mathrm{~min}$, using a $50 \mathrm{ng} / \mathrm{mL}$ PSA solution. In Figures 2d-f, all other conditions were same in Figures 2a-c, except that the reaction between the mab-PSA and the PSA was performed in a low-ionicstrength $(10 \mu \mathrm{M} \mathrm{PB})$ reaction. When the high-ionic-strength reaction buffer solution was used, the number of Nps resulting from the mab-PSA-PSA binding reaction remained constant regardless of the duration of washing step with the low-salt buffer solution (Table 1). However, when the low-ionic-strength reaction buffer solution was used, the number of Nps resulting from the mab-PSA-PSA binding reaction was gradually decreased with the duration of the washing process (Table 1). Compared to the number of Nps without washing in Figure $2 \mathrm{~d}$, the number of Nps was reduced by $67 \%$ and $95 \%$, after 10 and 30-min washing, respectively. The result in Figure $2 \mathrm{~g}$ was obtained when the flow of PSA onto the Si substrate coated with the mab-PSA was omitted, while the pab-PSA Au-Np conjugate solution was still injected onto the Si substrate for $1 \mathrm{~h}$. Such experiment was for examining the non-specific binding of the pab-PSA Au-Np conjugates onto the Si substrate covered with the mab-PSA. The number of Nps after the non-specific binding process was as low as $4 \%$ of that was obtained without washing (Figure 2d), similar to the value after washing for 30 $\min$ (Figure $2 \mathrm{f}$ ). Therefore, it can be concluded that, by washing for $30 \mathrm{~min}$, the majority of the PSA antigen can be removed from mab-PSA and PSA complexes. Table 2 shows the degree of the antigen-antibody binding according to the ionic strength of the reaction solution, as measured using ELISA. The ionic strength of the reaction solution was varied as shown in Table 2 , and all reaction buffer solutions were of $\mathrm{pH} 7.4$. The washing buffer solutions were all $10 \mu \mathrm{M}$ PB. The $5 \mathrm{ng} / \mathrm{mL}$ PSA was 

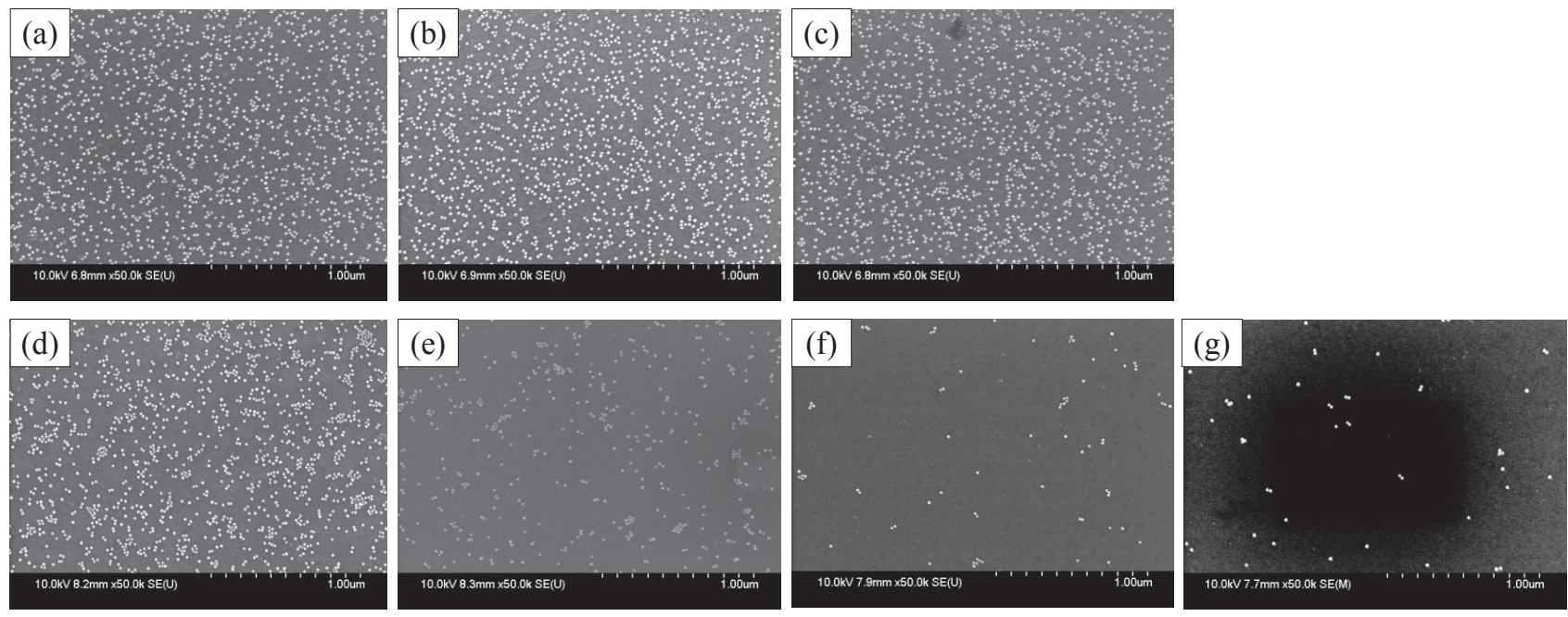

Figure 2. SEM images showing the dependence of the weak/strong binding reaction between antigen and antibody on the ionic strength of reaction solutions. (a)-(c): PSA-mab-PSA binding reaction followed by washing for (a) 0 , (b) 10, (c) 30 min in low-ionic-strength $10 \mu \mathrm{M}$ PB after the PSA binding reaction for $30 \mathrm{~min}$ in a high-ionic-strength $1 \times \mathrm{PBS}$ solution. (d)-(e): PSA-mab-PSA binding reaction followed by washing for (d) 0 , (e) 10, (f) $30 \mathrm{~min}$ in low-ionic-strength $10 \mu \mathrm{M}$ PB after the PSA binding reaction for $30 \mathrm{~min}$ in low-ionic-strength $10 \mu \mathrm{M}$ PB. (g) Non-specific binding test.

Table 2. Degree of the antigen-antibody binding according to the ionic strength of the reaction buffer solution, as evaluated using the sandwichtype ELISA

\begin{tabular}{ccccc}
\hline PSA & initial [PSA] & reaction buffer solution $(\mathrm{pH} 7.4)$ & measured [PSA] & initial [PSA]/measured [PSA] \\
\hline a & 0 & $1 \times$ PBS (no PSA) & 0 & 0 \\
b & $5 \mathrm{ng} / \mathrm{mL}$ & $1 \times$ PBS & $4.56 \mathrm{ng} / \mathrm{mL}$ & 1 \\
c & $5 \mathrm{ng} / \mathrm{mL}$ & $0.1 \times \mathrm{PBS}$ & $4.47 \mathrm{ng} / \mathrm{mL}$ & 0.98 \\
d & $5 \mathrm{ng} / \mathrm{mL}$ & $0.01 \times \mathrm{PBS}$ & $3.23 \mathrm{ng} / \mathrm{mL}$ & 0.71 \\
e & $5 \mathrm{ng} / \mathrm{mL}$ & $0.001 \times \mathrm{PBS}$ & $2.20 \mathrm{ng} / \mathrm{mL}$ & 0.48 \\
f & $5 \mathrm{ng} / \mathrm{mL}$ & $0.0001 \times \mathrm{PBS}$ & $1.37 \mathrm{ng} / \mathrm{mL}$ & 0.30 \\
\hline
\end{tabular}

quantified by using PBS solutions of various concentrations $(1 \times$ PBS, $0.1 \times$ PBS, $0.01 \times$ PBS, $0.001 \times$ PBS , and $0.0001 \times$ PBS $)$. As the ionic strength of the reaction solution was reduced, the amount of antigen measured by ELISA also decreased (Table 2) as follows: $98 \%$ in $0.1 \times \mathrm{PBS}, 71 \%$ in $0.01 \times \mathrm{PBS}, 48 \%$ in $0.001 \times \mathrm{PBS}$, and $30 \%$ in $0.0001 \times \mathrm{PBS}$. Such results suggest that the effect of ionic strength of the reaction buffer on dissociation of the antigen can be smaller than that was estimated by the pab-PSA Au-Np conjugate immunoassay. However, we can still see that the overall dependence of PSA dissociation on the ionic strength of the reaction solution analyzed by ELISA is similar to that was obtained by pab-PSA Au Np conjugates immunoassay. The discrepancy in detailed Figures can be attributed to the difference in the washing method employed in each immunoassay. In the pab-PSA Au-Np conjugate immunoassay, the antigen-antibody complex was washed in the microfluidic chip using a flow rate of $25 \mu \mathrm{L} / \mathrm{min}$. In contrast, washing in the ELISA involved dipping the microtiter plates into washing solution followed by shaking.

Figure 3a shows the weak (reversible) PSA-mab-PSA specific binding reaction measured in a low-ionic-strength reaction solution, as detected using a p-type doped Si FET biosensor. The conductance was measured while a $1 \mathrm{ng} / \mathrm{mL}$ PSA reaction solution and a reference buffer solution was supplied alternatively.
Step 1 corresponds to the reference buffer solution, and step 2 corresponds to the reaction solution containing $1 \mathrm{ng} / \mathrm{ml}$ PSA. The reference buffer solution of step 1 and the reaction solution of step 2 were composed of the same $\mathrm{pH}$ and ion concentration (pH 6 and $10 \mu \mathrm{M} \mathrm{PB}$ ). When the reference buffer solution without PSA was injected, the conductance increased (Step 1). When the reaction solution containing PSA ( $\mathrm{pI} \sim 6.8)$, which carried a net positive charge at $\mathrm{pH} 6$, was supplied onto the p-type doped Si FET, the conductance decreased, returning to the original value (Step 2). This result was consistent with previous reports. ${ }^{6,7}$ A return to the initial conductance $\left(\mathrm{G}_{2}\right)$ upon the injection of PSA reaction solution is because PSA is bound to the surface-linked mab-PSA. When the reference buffer solution is supplied, the conductance increases because the antigenantibody complex is re-dissociated. Signal conductance $\Delta G$ is obtained by the difference of the saturation conductances $\mathrm{G}_{1}$ and $\mathrm{G}_{2} . \Delta \mathrm{G}$ was $33 \mathrm{nS}$, and $\Delta \mathrm{G} / \mathrm{G}_{1}$ was $12 \%$. These results suggest that the reaction is weak (reversible) in this condition with alternating formation and dissociation of the antigen-antibody complex in a low ionic-strength reaction solution. In contrast, in a high-ionic-strength reaction solution (Figure 3b), a strong PSA-mab-PSA specific binding reaction was observed. Changes in electric conductance were measured for mab-PSA-immobilized Si channels, where step 1 corresponds to the reference 
(a)

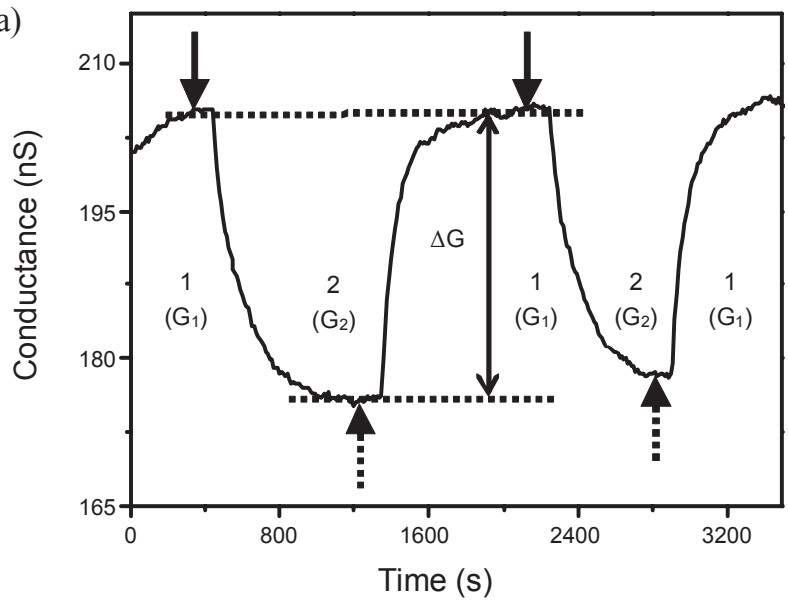

(b)

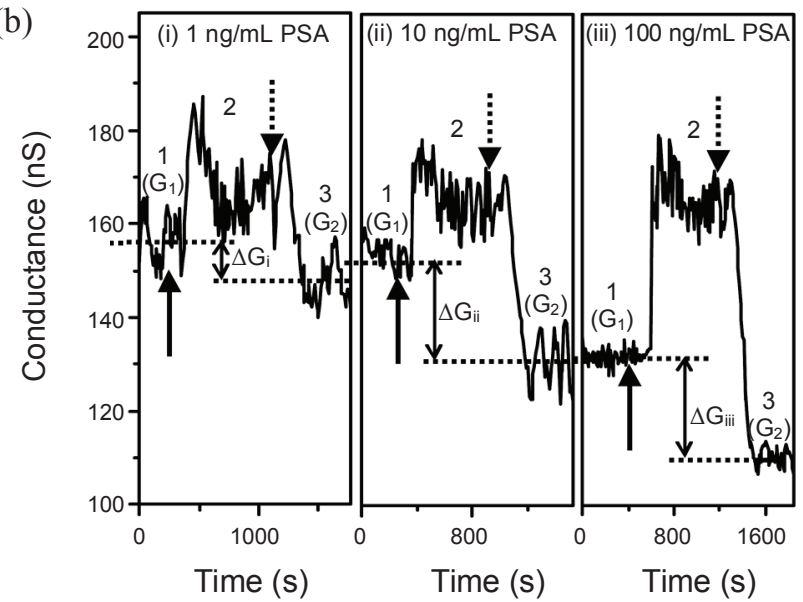

Figure 3. (a) A weak (reversible) PSA-mab-PSA specific binding reaction measured by a p-type doped Si FET sensor. The width/length/height $(\mathrm{W} / \mathrm{L} / \mathrm{H})$ of Si FET channel is $150 \mathrm{~nm} / 5 \mu \mathrm{m} / 40 \mathrm{~nm}$. Conductance $v s$. time for a mab-PSA-terminated Si channel, where step 1 corresponds to reference buffer solution, and step 2 corresponds to the addition of reaction solution containing $1 \mathrm{ng} / \mathrm{mL}$ PSA. The conductance was measured by alternating the flow between a $1 \mathrm{ng} / \mathrm{mL}$ PSA reaction solution and a reference buffer solution. Ion concentration and $\mathrm{pH}$ of the reference buffer solution and reaction solution are the same $(10 \mu \mathrm{MPB}$ and $\mathrm{pH} 6$, respectively). (b) A strong PSA-mab-PSA specific binding reaction in a $1 \times \mathrm{PBS}$ buffer reaction solution was measured by a p-type doped Si FET sensor. The W/L/H is $150 \mathrm{~nm} / 5 \mu \mathrm{m} / 40 \mathrm{~nm}$. Conductance $v s$. time for a mab-PSAterminated Si channel, where step 1 corresponds to reference buffer solution, step 2 corresponds to the addition of reaction solution containing (i) 1 , (ii) 10 , and (iii) $100 \mathrm{ng} / \mathrm{ml} \mathrm{PSA} \mathrm{(in} 1 \times \mathrm{PBS}$ and $\mathrm{pH} 7.4$ ), and step 3 corresponds to reference buffer solution. Step 1 and step 3 used the same reference buffer solution (10 $\mu \mathrm{M}$ PB and $\mathrm{pH}$ 6). The solid arrow sign indicates the addition of PSA reaction solution, and the dotted arrow sign represents the addition of the reference buffer solution.

(a)

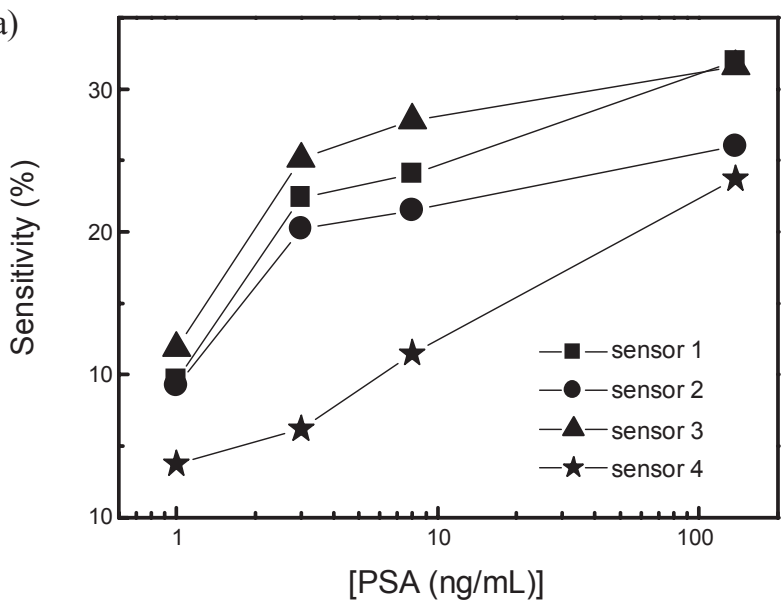

(b)

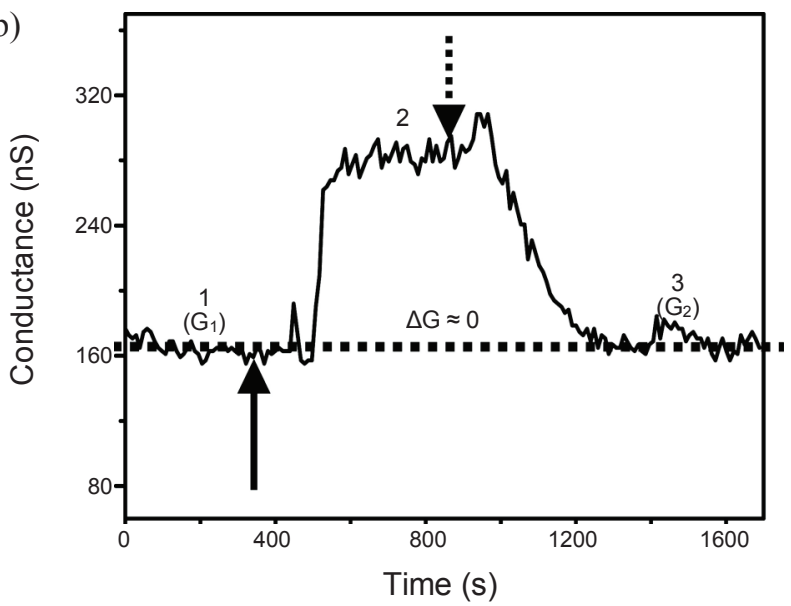

Figure 4. (a) Sensitivity $(\angle \mathrm{G} / \mathrm{G}) v s$. logarithm of PSA concentration data and sensitivities as a function of channel conductance for four individual sensors (W/L/H: $300 \mathrm{~nm} / 10 \mu \mathrm{m} / 40 \mathrm{~nm} / 220 \mathrm{~nm} / 2 \mu \mathrm{m} / 40 \mathrm{~nm}, 180 \mathrm{~nm} / 2 \mu \mathrm{m} / 40 \mathrm{~nm}$, and $5000 \mathrm{~nm} / 20 \mu \mathrm{m} / 40 \mathrm{~nm}$ for sensor 1, 2, 3, and 4, respectively). (b) Nonspecific binding test. The W/L/H is $150 \mathrm{~nm} / 5 \mu \mathrm{m} / 40 \mathrm{~nm}$. Conductance $v s$. time for an anti-PSA-terminated Si channel, where step 1 corresponds to reference buffer solution $(10 \mu \mathrm{M} \mathrm{PB}$ and $\mathrm{pH}$ 6), step 2 corresponds to the addition of $10 \%$ BSA $1 \times \mathrm{PBS}$ solution, and step 3 corresponds to reference buffer solution. The solid arrow indicates the addition of $10 \%$ BSA reaction solution, and the dotted arrow sign represents the addition of a reference buffer solution.

buffer solution $\left(\mathrm{G}_{1}\right)$, step 2 corresponds to the the reaction solution $(1 \times \mathrm{PBS}$, $\mathrm{pH} 7.4)$ containing 1,10 , and $100 \mathrm{ng} / \mathrm{mL}$ PSA, and step 3 corresponds to reference buffer solution $\left(\mathrm{G}_{2}\right)$ (Figure $\left.1 \mathrm{a}\right)$. Step 2 allows the binding reaction between PSA and the mabPSA to proceed for $15 \mathrm{~min}$ in $1 \times \mathrm{PBS}$ ( $\mathrm{pH} 7.4$ ) reaction solution $(1 \times$ PBS, Debye length $\sim 0.7 \mathrm{~nm}){ }^{3}$ In Figure $3 \mathrm{~b}$, the saturation conductance $\mathrm{G}_{1}$ was measured while flowing the reference buffer solution (step 1), and $\mathrm{G}_{2}$ was measured while reflowing the reference buffer solution and removing the remaining PSA solu- tion (step 3). As calculated from Figure $3 \mathrm{~b}, \Delta \mathrm{G}_{\mathrm{i}}$ and $\Delta \mathrm{G}_{\mathrm{i}} / \mathrm{G}_{1}$ were $6 \mathrm{nS}$ and $3.8 \%, \Delta \mathrm{G}_{\mathrm{ii}}$ and $\Delta \mathrm{G}_{\mathrm{ii}} / \mathrm{G}_{2}$ were $21 \mathrm{nS}$ and $13.8 \%$, and $\Delta \mathrm{G}_{\mathrm{iii}}$ and $\Delta \mathrm{G}_{\mathrm{iii}} / \mathrm{G}_{3}$ were $22 \mathrm{nS}$ and $16.5 \%$, respectively. The solid arrow indicates the time when PSA reaction solution began to flow, while the dotted arrow represents the addition of the reference buffer solution. Compared to the conductance in step 1, the conductance in step 2 was increased, which can be attributed to several factors: (1) the difference in $\mathrm{pH}$ and ion concentration between the two solutions; (2) the change in charges of mab- 


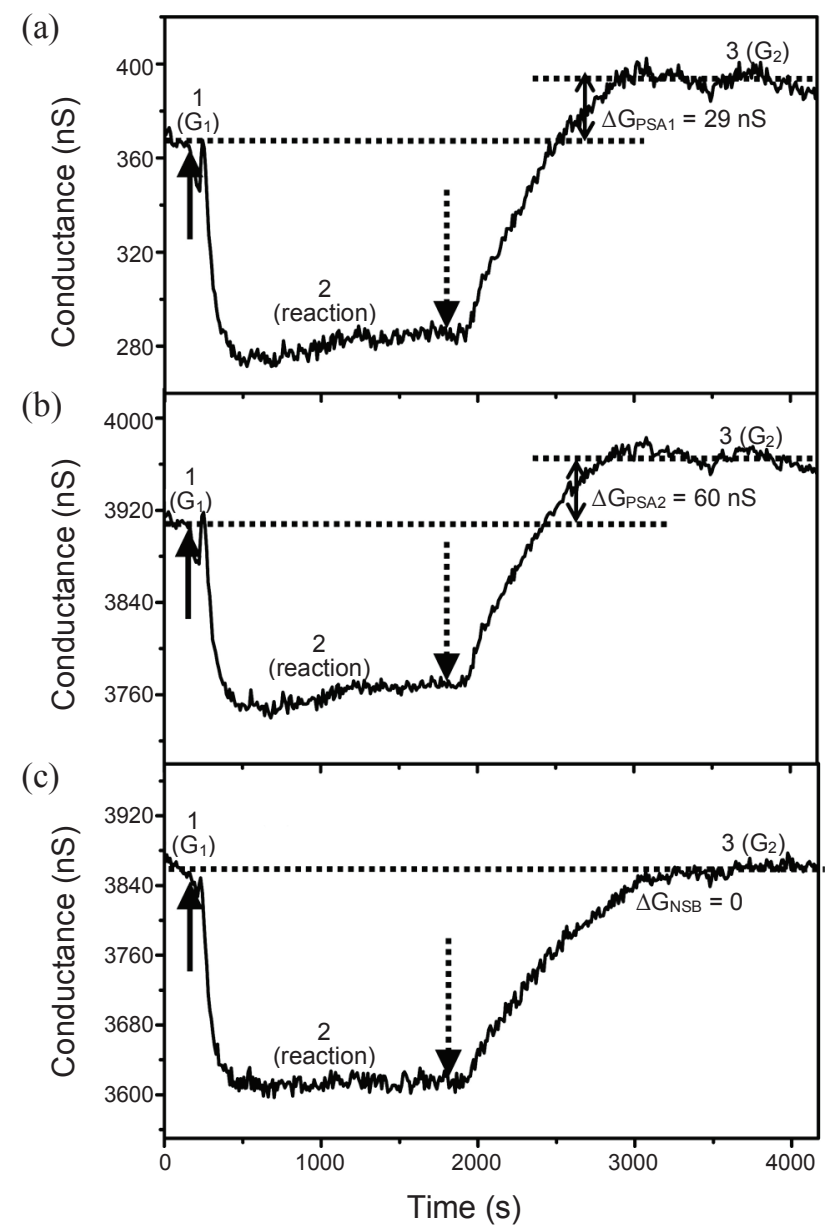

Figure 5. The plots of conductance versus time for undiluted electronic detection of PSA in human serum reaction solutions by $(a, b)$ a mabPSA- and (c) IgG-terminated p-type doped Si FET biosensor. Region 1 corresponds to reference buffer solution $(10 \mu \mathrm{M} \mathrm{PB}$ and $\mathrm{pH} 8)$, region 2 corresponds to the addition of human serum containing $10 \mathrm{ng} / \mathrm{mL}$ PSA, and region 3 corresponds to reference buffer solution $(10 \mu \mathrm{M} \mathrm{PB}$ and $\mathrm{pH} 8$ ). (a) The dimension (W/L/H) was $180 \mathrm{~nm} / 5 \mu \mathrm{m} / 40 \mathrm{~nm}$ and $\angle \mathrm{G}$ was $29 \mathrm{nS}$ and $\angle \mathrm{G} / \mathrm{G}_{1}$ was $7.3 \%$,(b) $1000 \mathrm{~nm} / 20 \mu \mathrm{m} / 40 \mathrm{~nm}$ and $60 \mathrm{nS}$ and $1.5 \%$, and (c) $1000 \mathrm{~nm} / 20 \mu \mathrm{m} / 40 \mathrm{~nm}$ and $\sim 0 \mathrm{nS}$ and $\angle \mathrm{G} / \mathrm{G}_{1}$ was $\sim 0 \%$ (a nonspecific binding test).

PSA caused by pH change; (3) newly added charges of PSA specifically bound to surface-linked mab-PSA. Unlike the result observed for the low-ionic-strength reaction solution in Figure $3 \mathrm{a}$, when the reference buffer solution was injected again in step 3, the conductance was not restored to the initial value in step 1, but became rather smaller (Figure 3b). Step 1 and step 3 used the same reference buffer solution $(10 \mu \mathrm{M}$ PB and $\mathrm{pH}$ $6)$. At pH 6, PSA ( $\mathrm{pI} \sim 6.8)$ is positively charged. Thus, if the PSA is bound to the mab-PSA, the depletion of holes occurs within the p-type Si channel, and the conductance is reduced. Such results demonstrate that in a high-ionic-strength reaction solution, the specific binding reaction between antigen and antibody is strong, unlike the weak (reversible) reaction observed in a low-ionic-strength reaction solution. Figure 4 a shows sensitivity $(\Delta \mathrm{G} / \mathrm{G}) v s$. logarithm of PSA concentration data for four individual sensors with different dimensions, which demonstrate the feasibility of this approach for quantitative sens- ing ( 1 - 140 ng/mL PSA). In addition, as shown in Figure 4b, a control experiment was performed to confirm that the observed results are due to the specific PSA-mab-PSA binding reaction. The electric conductance was monitored for mab-PSA-terminated Si channels, where step 1 corresponds to the reference buffer solution $(10 \mu \mathrm{M}$ PB and $\mathrm{pH} 6)\left(\mathrm{G}_{1}\right)$, step 2 corresponds to the $10 \%$ BSA $1 \times$ PBS solution, and step 3 corresponds to the reference buffer solution $\left(\mathrm{G}_{2}\right)$. In this case, $\Delta \mathrm{G}$ was $\sim 0 \mathrm{nS}$, indicating that the supply of BSA causes no change in the conductance, with little nonspecific binding reaction.

Figure 5 shows the plots of conductance versus time for electronic detection of PSA in human serum reaction solutions by a mab-PSA (Figure 5a and b)-and IgG (Figure 5c)-terminated p-type Si FET biosensor, where region 1 corresponds to reference buffer solution ( $10 \mu \mathrm{M}$ PB and $\mathrm{pH} 8)$, region 2 corresponds to the eaction solutions containing $10 \mathrm{ng} / \mathrm{mL}$ PSA (human serum), and region 3 corresponds to reference buffer solution (10 $\mu \mathrm{M}$ PB and $\mathrm{pH} 8)$. Region 2 allows the binding reaction between PSA and the mab-PSA to proceed for 20 min in human serum. The solid arrow indicates the addition of PSA and the dotted arrow sign represents the addition of the reference buffer solution. The saturation conductance $\mathrm{G}_{1}$ was measured in the flowing reference buffer solution (region 1 ), and $\mathrm{G}_{2}$ was measured after removing the remained PSA solution by reflowing the reference buffer solution (region 3). At pH 8, PSA ( $\mathrm{pI} \sim 6.8$ ) is negatively charged; thus, if the PSA is bound to the mab-PSA, hole accumulation occurs and the conductance is increased. For the dimension $(\mathrm{W} / \mathrm{L} / \mathrm{H})$ of $180 \mathrm{~nm} / 5 \mu \mathrm{m} / 40 \mathrm{~nm}$ (Figure 5a) and $1000 \mathrm{~nm} / 20 \mu \mathrm{m} / 40 \mathrm{~nm}$ (Figure $5 \mathrm{~b}$ ), $\Delta \mathrm{G}_{\mathrm{PSA} 1}$ and $\Delta \mathrm{G}_{\mathrm{PSA} 2}$ was $29 \mathrm{nS}$ and $60 \mathrm{nS}$. A sensitivity ( $\left.\Delta \mathrm{G} / \mathrm{G}_{\mathrm{PSA}}\right)$ for the small dimension of $180 \mathrm{~nm} / 5 \mu \mathrm{m} / 40 \mathrm{~nm}$ (Figure $5 \mathrm{a}$ ) is $7.3 \%$, which is larger than $\Delta \mathrm{G} / \mathrm{G}_{\mathrm{PSA} 2}$ of $1.5 \%$ observed for the larger dimension, $1000 \mathrm{~nm} / 20 \mu \mathrm{m} / 40 \mathrm{~nm}$ (Figure 5b). For nonspecific binding test for the dimension of $1000 \mathrm{~nm} / 20 \mu \mathrm{m} / 40 \mathrm{~nm}$ (Figure 5c), $\Delta \mathrm{G}_{\mathrm{NSB}}$ and $\Delta \mathrm{G} / \mathrm{G}_{\mathrm{NSB}}$ was $\sim 0 \mathrm{nS}$ and $\sim 0 \%$, meaning that nonspecific binding can be ignored.

These results regarding the weak/strong antigen-antibody binding (non-covalent) could be explained by mutual-binding forces, each of which is an important contributor to antigenantibody binding. The forces that can contribute to antigenantibody binding are hydrogen bonds, electrostatic attractions, hydrophobic interactions, and van der Waals force interactions. Because these bonds are weak compared with covalent bonds individually, numerous non-covalent interactions are required for the formation of strong antigen-antibody interactions. The ionic strength effect on hydrogen bond interactions shows a reduction of its combination force as ionic strength increases. ${ }^{18}$ Similarly, the ionic strength effect on electrostatic interactions is known as that electrostatic interactions between proteins decrease as ionic strength increases. ${ }^{19,20}$ In contrast, the strength of hydrophobic bonds is enhanced by increasing the salt concentration. ${ }^{21}$ In protein structures, hydrogen bonds, electrostatic attractions, and hydrophobic bonds have similar binding strengths, while the van der Waals forces are much weaker, making a relatively small contribution to protein-protein binding. Regarding protein-protein binding, previous researches have suggested that the area occupied by hydrophobic binding at the proteinprotein interface represents more than $2 / 3$ (two-thirds of the 
buried surface) of the total area. ${ }^{22-24}$ Chothia et al. reported ${ }^{22}$ that hydrophobicity is the major force that stabilizes protein-protein interactions, while complementarity plays a selective role in deciding which proteins form associations, e.g., insulin dimers, trypsin-pancreatic inhibitor complex, and oxyhemoglobin dimers. Moreover, Goto reported ${ }^{24}$ that the accessible hydrophobic surface areas that are buried between the enzyme and the primary contact step are proportional to their experimental binding energies, indicating that the hydrophobic interaction strongly drives enzyme-protein binding. Generally, the proteinprotein mutual-binding force/energy that is due to non-covalent interactions depends largely on the salt concentration of the solution, ${ }^{18-22}$ and protein-protein mutual-binding energy increases with the salt concentration. ${ }^{19,21}$ In the present study, the reversibility of antigen-antibody binding decreased as the ionic strength increased. For that reason, we speculate that the primary explanation for such observation is that the contribution of hydrophobic interactions exceeds those of both hydrogen bonds and electrostatic interactions. ${ }^{22,23}$

\section{Conclusions}

The results of the present study demonstrates a new method for electronic detection of biomarkers from undiluted solutions, using weak/strong specific binding properties which are strongly dependent on the ionic strength of the reaction solution. This result is very important because it is also relevant to antibody recycling, and can provide new findings, applications, and details with regard to the fundamental events of antigen-antibody binding. In particular, Si FET biosensors, which are the object of intensive research for a new protein-analysis method, are simple to manufacture by either "bottom-up" or "top-down" approaches. Si FET biosensors have very high detection sensitivity-in the range of tens of femtograms per milliliter. ${ }^{6}$ The results of the present study showed that we can induce both reversible and irreversible changes in conductance, depending on the ionic strength of the reaction solutions containing target molecules. This work shows that the binding or unbinding of proteins could be monitored directly in a high-ionic-strength reaction solution, such as $1 \times \mathrm{PBS}$ and human serum, using a Si FET biosensor without any desalting or dilution, by employing a new detection scheme independent on the ionic strengths of raw sample solutions.
Acknowledgments. This work was partly supported by the Ministry of Knowledge Economy in Korea [2009-F-008-01, Programmable Bio-CMOS Field-Effect Transistors] and the KOCI [09ZC1410, Basic Research for the Ubiquitous Life Care Module Development]. We thank Hye Kyoung Yang for technical supports.

\section{References}

1. Elfström, N.; Karlström, A. E.; Linnros, J. Nano Lett. 2006, 8, 945.

2. Zhang, G.-J.; Zhang, G.; Chua J. H.; Chee, R.-E.; Wong, E. H.; Agarwal, A.; Buddharaju, K. D.; Singh, N.; Gao, Z.; Balasubramanian, N. Nano Lett. 2008, 8, 1066.

3. Stern, E.; Wagner, R.; Sigworth, F. J.; Breaker, R.; Fahmy, T. M.; Reed, M. A. Nano Lett. 2007, 7, 3405.

4. Park, I.; Li, Z.; Li, X.; Pisano, A. P.; Williams, R. S. Biosens. Bioelectron. 2007, 22, 2065.

5. Heitzinger, C.; Klimeck, G. J. Comput. Electron. 2007, 6, 387.

6. Zheng, G.; Patolsky, F.; Cui, Y.; Wang, W. U.; Lieber, C. M. Nature Biotech. 2005, 23, 1294.

7. Kim, A.; Ah, C. S.; Yu, H. Y.; Yang, J.-H.; Baek, I.-B.; Ahn, C.-G.; Park, C. W.; Jun, M. S.; Lee, S. Appl. Phys. Lett. 2007, 91, 103901.

8. Abe, M.; Murata, K.; Kojima, A.; Ifuku, Y.; Shimizu, M.; Ataka, T.; Matsumoto, K. J. Phys. Chem. B 2007, 111, 8667.

9. Storhoff, J. J.; Elghanian, R.; Mucic, R. C.; Mirkin, C. A.; Letsinger, R. L. J. Am. Chem. Soc. 1998, 120, 1959.

10. Cloarec, J. P.; Martin, J. R.; Polychronakos, C.; Lawrence I.; Lawrence, M. F.; Souteyrand, E. Sens. Actuators B 1999, 58, 394.

11. Sakata, T.; Kamhori, M.; Miyahara, Y. Mater. Sci. Eng. C 2004, 24, 827.

12. Sakata, T.; Miyahara, Y. ChemBioChem 2005, 6, 703.

13. Howarter, J. A.; Youngblood, J. P. Langmuir 2006, 22, 11142.

14. Bunimovich, Y. L.; Shin, Y. S.; Yeo, W.-S.; Amori, M.; Kwong, G.; Heath, J. R. J. Am. Chem. Soc. 2006, 128, 16323.

15. Uno, T.; Tabata, H.; Kawai, T. Anal. Chem. 2007, 79, 52.

16. Mcalpine, M. C.; Ahmad, H.; Wang, D.; Heath, J. R. Nature Mater. 2007, 6, 379.

17. Park, H.-J.; Kim, S. K.; Park, K.; Lyu, H.-K.; Lee, C.-S.; Chung, S. J.; Yun, W. S.; Kim, M.; Chung, B. H. FEBS Lett. 2009, 583, 157.

18. Chandra, A. Phys. Rev. Lett. 2000, 85, 768.

19. Lee, K. K.; Fitch, C. A.; Garcia-Moreno E. B. Protein Sci. 2002, 11, 1004.

20. Chang, B. H.; Bae, Y. C. Biomacromolecules 2003, 4, 1713.

21. Curtis, R. A.; Montaser, U. A.; Prausnitz, J. M.; Blanch, H. W. Biotechnol. Bioeng. 2002, 79, 367.

22. Chothia, C.; Janin, J. Nature 1975, 256, 705.

23. Chothia, C. Nature 1974, 248, 338.

24. Goto, K. Biochem. Biophys. Res. Commun. 1995, 206, 497. 